\title{
Compartir una experiencia del aula con mayores de la Universidad de Cádiz. Ver la televisión
}

\author{
Sharing classroom experiences with old people of the University of \\ Cadiz. Watching Television \\ Compartilhar experiências de sala de aula com idosos da Universidade \\ de Cádiz. Assistir televisão
}

\author{
Víctor Manuel Amar Rodríguez
}

"Aprender más cosas sobre el mundo, enriquece nuestra experiencia en él" Profesor Dr. Daniel J. Levitin

\begin{abstract}
El hecho de compartir en un foro como este una experiencia docente puede llegar a resultar, valiéndonos de un símil, como si a una persona extraña a nuestra cotidianeidad del aula le vayamos a permitir introducirse $\mathrm{y}$, sintiéndonos observándolo, veamos como toma notas, asunta con la cabeza cuando está de acuerdo con nuestra forma de proceder o bien, simplemente, niega con un gesto mostrando su disconformidad. A todas luces, deseamos hacerles llegar esta reflexión inspirada en la práctica que ocupa parte de nuestra docencia en el Aula de Mayores de la Universidad de Cádiz. Una asignatura que tiene 20 horas de docencia distribuidas en diez días en sesiones de dos horas, con el título de "Ver televisión con las personas mayores", que lleva cinco años siendo impartida en los tres campus, de los cuatro, con que cuenta esta Universidad: Cádiz capital, Jerez de la Frontera y Algeciras.

En cada aula suele haber una media de 30 a 40 alumnos y alumnas, todos mayores de 55 años de edad. Su perfil profesional es de lo más variado pues hay desde profesores de la propia Universidad que una vez jubilados han deseado seguir con otro tipo de actividad académica, hasta personas que toda su vida han estado trabajando en el sector servicio o en el tejido industrial de la provincia gaditana y ahora intenta revalidar algunos conocimientos que durante años y por circunstancias tuvieron que dejar aparcados. Asimismo, hay mujeres (amas de casa) ya con hijos mayores que cuando se les pregunta responden qué pretenden alcanzar con esta experiencia formativa sostienen que: aquella que no pudimos disfrutar cuando éramos jóvenes por varias razones:
\end{abstract}

a) no teníamos demasiadas posibilidades para estudiar, b) la crianza de nuestros hijos o el matrimonio, y c) las menos, tuvimos que responder a exigencias laborales fuera del hogar privándonos del acceso a la Universidad (para más información Memoria Aula Universitaria de Mayores de la Universidad de Cádiz http://www.uca.es/aula/mayores/drago-05.pdf [consultada el 18 de octubre de 2010]).

La primera jornada comienza con el saludo pertinente y la presentación de la asignatura. Para esta ocasión intentamos introducir la materia a ser impartida como un pretexto para presentarnos también nosotros. Por ejemplo, hablando de los propósitos de la asignatura hacemos alusión a cada uno de ellos pero la intención no sería cumplirlos de modo obsesivo sino crear un clímax de aprendizaje donde se vayan generando y sucediéndose situaciones de aprendizaje con la finalidad de que los propósitos sean una mira y no un objetivo (según las teorías presentadas por José Gimeno (1998) y Fernando Hernández y Juana Sancho (2002)). En este sentido, aprovechamos la ocasión para hablar de la diferencia que existe entre objetivo y propósito en educación. Algo que ellos y ellas, con sus edades, tienen más que superado pues van a la "Universidad de la Experiencia" con la intención no tan sólo de aprender lo que ya viene en los libros o el profesorado se empeña en transmitir sino que acuden a ella con otros propósitos infundados en el aprendizaje compartido y dialogado inspirado en el debate de temáticas, relación de experiencias o comprensión de los contenidos.

Tras la presentación de la asignatura que, insistimos, mantiene una doble intención pasamos a centrar el primero 


\section{Introducción (la pregunta)}

- Cuánto tiempo se pasa frente a la TV (y los menores en la escuela)

- Cuántos aparatos hay por hogar (y en qué cuartos se ubican)

- Cómo se vela televisión

- Cuántas c adenas hay (estatal, autonómica, local, satélite, plataforma digital, cable...)

Qué se emite en la televisión

- Conocen ellenguaje, discurso y técnica de la tv

de los contenidos. Para ello, y será una constante, contamos con la ayuda de soporte informático - una presentación colectiva en power point. Un trabajo que realizamos con la intención que funcione como un esquema visual, de rápida lectura y fácil comprensión de los contenidos presentados. No obstante, estos contenidos están muy relacionados con su día a día. O sea, con cómo y qué ven en la televisión, desglosado en preguntas directas que se pretenderán dar respuesta en la propia clase. A todas luces, estamos ante un alumnado que participa y que se comunica con el profesor y con los demás compañeros y compañeras. Una vez se ha comenzado a participar y se han dado respuesta a las preguntas planteadas, lo que se pretende es finalizar la primera transparencia con otra pregunta más: En ocasiones, ¿en nuestras casas tenemos más televisiones qué miembros existen en el hogar?

Con ello, la sesión no finaliza pues continúa en el debate abierto y los discursos docentes no se cierran sino que se dejan abiertos para que el alumnado los vaya completando paulatinamente, sin importar en qué momento o contexto.

La primera clase concluye con la visualización y comentario de un vídeo que se baja de Internet. Para ello, les explicamos que existe una página disponible en el servidor de la Universidad en la cual estos documentos audiovisuales se pueden consultar. Les hacemos ver que últimamente hasta el modo de dar las clases han cambiado con respecto a cuando ellos estaban en sus colegios o institutos. Ahora el profesorado, al menos en nuestro caso, va sin papeles al aula y todo está en red. Claro está que no falta alumnado que se muestra disconforme con esta forma de presentar los materiales, pues se refieren a que existe una dependencia de Internet y pregunta: ¿y si éste falla? La respuesta no se hace esperar pues les comentamos que en los pen driver o usb el material está igualmente almacenado y si falla Internet, ahí tenemos otro recurso. La idea que se establece es que no se trata de enfrentarse a las tecnologías de la información y la comunicación sino aliarse con ella. Y, también, les comentamos que entre ellos que pueden tener más de 50, 60 ó 70 años y la del profesorado que está en torno a los 40 existe menos diferencias que entre el profesor que les imparte la asignatura y los niños y niñas que están en la escuela, es decir, por ejemplo con sus nietos. Nosotros, tanto ellos como el profesor, somos analógicos y los jóvenes son digitales. Sin embargo, hemos de aprender todo los días y mantener actitudes para ello; simplemente, hace falta tener disposición. Siempre acostumbramos comentarles algún viejo refrán castellano y en esta ocasión hacemos referencia al que dice "No hay peor ciego que el que no quiere ver"; haciendo alusión a la voluntad que necesitamos para aprender en tiempo presente, inclusive, a ver la televisión. Una televisión que ya no es paleotelevisión sino que ha evolucionado con el advenimiento de las nuevas tecnologías. Un mundo de las pantallas que nos invade y se habla de iconosfera, de iconomía (un juego de palabra con economía e icono)... Y, por último, les invitamos a hacer un poco de tarea/deberes en sus casas. Por ejemplo, que se sienten a ver la televisión y apunten en un papel los contenidos de la programación, el papel de la publicidad televisiva y qué emiten en varias cadenas en un mismo intervalo.

La segunda jornada la empezamos haciendo un repaso de los deberes mandados en la primera clase. La primera pregunta (qué ven en la televisión) ellos y ellas la responden intercambiando opiniones que, también, cuenta con las del profesor. La segunda cuestión (sobre la publicidad) intentamos que reparen en los mensajes que se emiten, la mujer objeto, los roles sexista, el uso y el abuso ecológico para reclamar un producto, el alcohol, el modelo de vida y alimentación, etc. y acabamos esta parte advirtiéndoles que la mayoría de las grandes cadenas televisivas parece que se ha puesto de acuerdo para emitir la publicidad y, a veces, en una cadena y otra cadena anuncian el mismo producto. Estamos ante un perfecto pretexto para hablar sobre la publicidad y la televisión. Nuestra intención es demostrarla de manera transversal pues la publicidad ha sabido evolucionar con los tiempos y dar respuesta a las demandas del mercado. Para ilustrar un poco el tema de la publicidad les ponemos varios ejemplos de anuncios de España y otras partes del mundo; se analizan y se pretende llegar a conclusiones consensuadas. El tercer y último apartado (el que hace alusión a los contenidos emitidos en un intervalo de tiempo) es el mejor momento que tenemos para hablarles de la mirada mosaico y que la nueva televisión ha evolucionado en Internet con lo que se conoce como "televisión a la carta". El tele-espectador puede elegir el programa, verlo, compartirlo con otros tele-videntes, grabarlo, etc. Ahora lo que no está en Internet no existe y lo que no existe no está en Internet (en este momento seguimos las enseñanza de Tubella y Dwyer (2008): Internet y televisión: la guerra de las pantallas). Para ello, los ejemplos que colocamos en la clase no sólo son de las televisiones españolas sino que, igualmente, entramos en páginas de televisiones de otras partes del mundo. Antes de finalizar esta clase les invitamos a que hagan un nuevo ejercicio en sus casas: que se detengan a pensar cómo vemos la televisión.

La tercera sesión, se comienza retomando la tarea del día anterior. El alumnado participa y nos detenemos en aspectos como que, la mayoría, ve la televisión en el sofá 
del salón pero muchos la prefieren ver desde su cama. Una situación idónea para introducir un nuevo "tópico" y trabajar las intenciones de la televisión. Simplemente, un dato para sugerirles el debate en relación con la gentileza que derrochamos día a día cuando encendemos la televisión en nuestra casa y permitimos que en la confortabilidad de nuestro hogar unos señores y señoras (con sus mensajes, con sus ideologías, con sus malos modos, etc.) penetren a través de la pantalla. Nosotros buscamos gratificación la mayoría de las veces que ponemos la televisión y, sin embargo, ellos nos mandan cientos de mensajes y nos mostramos inermes ante ellos. En primer lugar, no pensamos que en nuestra casa y nuestra televisión tenga malas intenciones y, en segundo término, no conocemos en profundidad ese lenguaje como para tener la suficiente capacidad para decodificarlo (aspectos sustentados en varios libros de referencia como Bourdieu (1997), García Matilla (2003) y Meirieu (2009)). Llevados por nuestra capacidad de fabulación, les contamos una historia cargada de inventiva que se resume en: en la ciudad de Tokio, allá por la década de los 80 , un desconocido candidato a la alcaldía se presentó ante la junta electoral y solicitó íntegramente el dinero de su campaña para hacer un vídeo electoral. No hubo problemas por parte de la autoridad y se le concedió su partida. Este señor hizo un vídeo y empezó a echarlo en muchos hogares de la ciudadanía de la capital japonesa. El día de las elecciones, ¿saben quién ganó la alcaldía? En efecto, el desconocido candidato a alcalde que se gastó todo su dinero en un vídeo. Es obvio que la discusión está sobre la mesa y que el alumnado se motiva pues le comentamos que, tal vez, la victoria no sólo vino por la credibilidad del mensaje sino que, también, por haberle permitido entrar en sus casas y compartir su mensaje electoral en vídeo cuando estamos cómodamente sentados, satisfechos después de nuestra cena y con cierta predisposición a que nos cuenten algo a modo de gratificación. Igualmente, hablando de la importancia e intención y poder de la televisión le hacemos referencia a la campaña del presidente Obama, a quien sus asesores le brindaron la oportunidad de transmitir un mensaje televisivo de costa a costa pues "alquiló" importantes cadenas televisivas para ocupar con su imagen y discurso todo este enorme espacio y población.

El cuarto día, con el alumnado lo que pretendemos es que cuestione a la televisión, sobre todo, en cuanto a sus intenciones. Para ello, la ponemos siempre en cuarentena y no dudamos en "sacarle los colores" siempre que podamos. Con ello, les indicamos al alumnado que, quizá, no podamos exigirle en exclusividad un cambio a la televisión pero si podemos tenerlo nosotros frente a ella. Para ellos leemos un documento (las recomendaciones de Valencia, 1999 (http:// www.wave-network.org/start.asp?ID $=20764 \& b=151$ [consultada el 18 de octubre de 2010]). que se les ha pasado en primer lugar a todos y todas de manera fotocopiada y luego aparece en la gran pantalla de la clase. Se le solicita a un alumno/a que lo lea en voz alta. La discusión se centra sobre las intenciones de la televisión y cómo es un importante agente de socialización. De modo que, centrándonos en el punto segundo de estas recomendaciones lo reproducimos en clase: "Un modo de aprender un comportamiento es observarlo" y, para ello, acompañamos varios ejemplos de la televisión de los años 70 (aún cuando vivía el dictador Francisco Franco) y de los años 80 (ya en plena democracia). Al alumnado se le hace saber que la peor censura no es la que impone los políticos, la económica o la religiosa sino que, a veces, es la autocensura y por ello, como profesor no me voy a censurar a la hora de hablar de determinados temas teniendo como pretexto la televisión de los años 70 ó 80 . En You Tube tenemos otro preciado recurso que muchos alumnos y alumnas ya conocen. Para esta clase nos valemos de dos programas: a) uno infantil de payasos y divertimiento titulado "Había una vez un circo"; cuando la televisión española era única y exclusiva del régimen franquista y b) ya en la transición y democracia española nuestra mirada se centra sobre un espacio de variedades en programación nocturna, titulado "Fiesta". En el primero vemos un mundo infantil e ingenuo con aventuras pueriles y un llamamiento a la familia convencional y unida. El segundo programa es una lección magistral de la evolución de la España pos-franquista donde hombres y mujeres se muestran desenfadados en la noche madrileña de la sala de fiesta Florida Park, con canciones que muestran una evolución en la sensibilidad generalizada, como por ejemplo con respecto a la mujer, y unos invitados que provienen de otras partes del mundo mostrándonos la televisión como una ventana a lo foráneo. La clase finaliza con la invitación a la lectura de otros documentos que les dejamos fotocopiados y nos despedimos con un ojalá la clase haya gustado, o no, pues mañana más y mejor.

El quinto día, sin previo aviso les ponemos un vídeo de una televisión local (previamente nosotros hemos elaborado un componente teórico a partir de los planteamientos de Hartley (2000), Martín Barbero (2000) y Chicharro y Rueda (2005)). La temática es sobre asuntos del día a día llevado como si de un debate se tratara, pero la consigna está en que el moderador del programa está en una silla de ruedas y todos los tertulianos son síndrome Down. Algunos reconocen la televisión pues es de su pueblo y otros la han podido ver alguna vez que otra haciendo zapping. Hablamos de qué están debatiendo estos chicos en la pantalla, por qué creen ellos que todos son síndrome Down, hacia dónde va la televisión... Les comentaremos que la sociedad española del siglo XXI ha cambiado. En cuestión de poco menos de veinte años hemos recibido una población emigrante de más de cinco millones de personas, hemos experimentado una evolución en los comportamientos sociales-afectivos, desde matrimonios mixtos, homosexuales, separaciones, adopciones, etc. $Y$ miren ustedes como se hace eco de estos cambios una "humilde" televisión de pueblo -con los cuales no tengo ninguna relación y no estoy haciendo publicidad de ella (intento provocar la sonrisa entre el alumnado)- escoge a un presentador que no mueve los pies ni las manos y está en una silla de ruedas y todos sus acompañantes son chicos diferentes a los que estamos acostumbrados a ver en las televisiones de más envergadura. Antes esos chicos eran los "tontos" del pueblo o mongólicos, luego pasaron a ser llamado síndrome Down y, en la actualidad, trisómicos. No es 
que sólo haya cambiado la palabra en su forma de referirse a estas personas sino también su semántica. Estos chicos ahora son actores de cine y premiados en festivales tan prestigiosos como el de San Sebastián, son profesores e, ya lo ven hasta tertulianos. Es decir, crean opinión pública y son motivo de que ahora nosotros y nosotras estamos refiriéndonos a ellos por hacer algo prosocial. Después de debatir, intentamos acabar la clase con otra frase que sugiera algo... En este caso, con la idea de dejar el debate en la cresta de la ola, vemos otros ejemplos que están en Internet. Nuestra intención ha sido la de recoger en una clase los primeros y últimos contenidos de la asignatura:

- La televisión en el siglo XXI

- $\quad$ Panorama televisivo: intereses, sentido y grupos mediáticos

- La educación con y para la ver la televisión

- De la alfabetización al conocimiento del discurso y la tecnología

- Criterios de análisis de la programación

- Por una capacidad crítica, analítica, además de responsable y activa

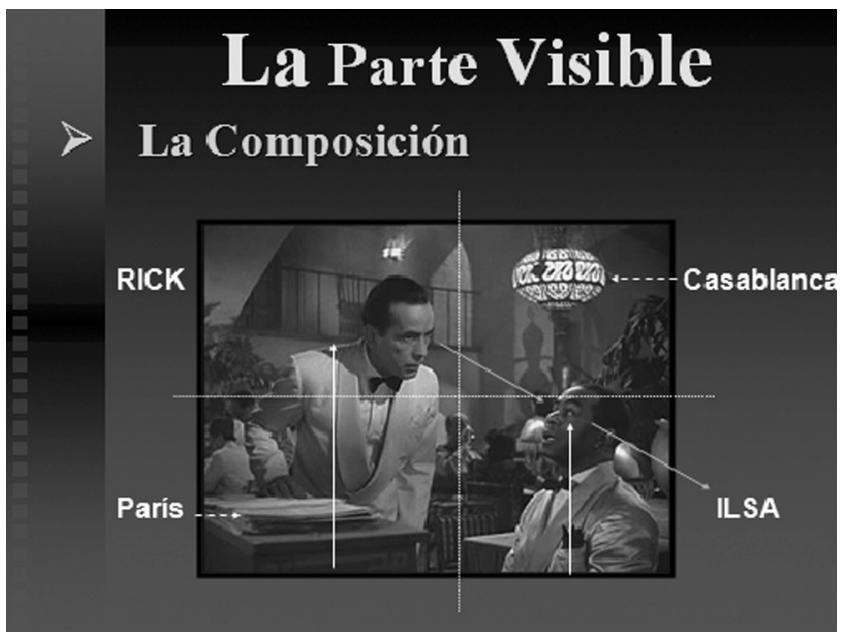

Al día siguiente, les pasamos una secuencia de la película "Casablanca". Un clásico del cine norteamericano que les trae muchos recuerdos. Ese puede que sea el motivo por la elección de esta cinta y la secuencia en cuestión es cuando Rick llega al bar y San está tocando "El tiempo pasará" al lado de Elsa y, seguidamente, la chica se encuentra con su pareja actual. Un triángulo amoroso que no ha envejecido a pesar del paso del tiempo. Un amor en el pasado de la chica junto a Rick y la ciudad de París y un amor en presente junto a Víctor en Casablanca.

La idea es muy sencilla con un film que la mayoría conoce empezar a trabajar la alfabetización audiovisual/televisiva (Amar, 2003, 2009; Castillo, 2009). Entendemos que en dos horas (lo que dura una clase) no se puede acceder a un nuevo alfabeto pero sí puede ser un buen motivo para relacionarse con él. Con ello, los apartados que desarrollamos a partir de la secuencia visionada son:

Parte visible.- Planificación, montaje, composición, movimiento, transición

Otra parte visible.- Pintura, literatura, música, cómic, arquitectura, fotografía

La parte invisible.- creación, subliminal, intereses, tecnología

El debate se sucede y se produce una reacción entre el alumnado que es la preocupación insistente y exagerada por encontrar planos y significados en todo lo que sea audiovisual. Esta experiencia nos hizo modificar los contenidos de esta clase para el sexto u octavo día pues puede quedar la clase en el anecdotario y no encontrarle el sentido suficiente. Llevados por lo nuevo olvidan o rechazan lo mucho que aún nos queda por ver y aprender. Por eso en los contenidos del día séptimo volvemos a un modelo más convencional donde la clase se imparte a partir de lo presentado en unas transparencias (power point) donde la temática social y educativa serán los principales acicates de la apuesta por reconducir la normalidad. Casi que es inevitable que cuando vemos algún vídeo (sea de la televisión o de Internet) los planteamientos de la clase anterior salen a relucir y, también, lo educativo o lo cultural son una gran preocupación para el alumnado (Ferrés, 1994; Rodríguez Pastoriza, 2003). Como madres y, a veces, como abuelas la adicción o el refugio a que son sometidos los más pequeños de la casa pues sus progenitores y nosotros mismos los conectamos frente a la niñera electrónica en que convertimos la televisión para que nos dejen tranquilos y poder hacer las labores del hogar o trabajar o prepararnos para el trabajo es un handicap que preocupa. El tema se habla en clase y les presentamos una batería de recomendaciones para ver la televisión con los chicos (que pasa por ejemplo: en verla con ellos, consensuar la programación, además de consultarla, saber encenderla del mismo modo que apagarla cuando nos aburre, conversar sobre el contenido de los programas y a veces hacer referencia a que nos quieren manipular...), además de darles en manera impresa un decálogo de buenas intenciones. Mientras que a nuestro alumnado del Aula de Mayores lo que, igualmente, les inquieta es el huésped alienante que tiene ante ellos en el seno de sus casas. Ya ven, compartimos preocupaciones y ya nos ocupa el analizarla y atajarla con coherencia. La televisión la ven y la analizan como si fuese un objeto de estudio. Ya no es simplemente gratificación, sin más, se trata de una herramienta para el disfrute y el aprendizaje que informa, forma y, como no podría ser menos, distrae. Antes de dar por finalizada la clase les proponemos durante unos minutos que digan en voz alta qué programas les apetecerían volver a ver y el por qué.

Ese mismo día, cuando llegamos a casa buscamos los programas que han dicho en clase y los encontramos en diferentes fuentes. En nuestro correo electrónico redi- 
reccionamos las páginas, con una pequeña leyenda debajo de éstas según sus contenidos, y cuando vayamos a clase tan sólo hemos de abrir nuestro e-mail y pinchar en el vídeo que deseamos. De este modo, estamos dándole forma a la clase del día octavo que es uno de los de mayor deleite para el alumnado que ven clásicos de la televisión española como el programa de debate "La clave", dirigido por José Luis Balbín, series como "Vacaciones en el mar", momentos estelares como la muerte del torero Paquirri, el 12 a 0 en el partido de fútbol entre España y Malta o el concurso "Un millón para el mejor". La intencionalidad de elección de estos programas fue de lo más variada desde el consenso por el programa "La clave" como uno de los mejores de la televisión de aquellos años del tardofranquismo, hasta el programa de concurso "Un millón para el mejor" pues uno de los alumnos fue participante y contó diferentes anécdotas de su experiencia en directo. La clase discurre entre expectación y emociones que invaden los sentimientos y produce una entrañable sensación de nostalgia contagiosa (López, Cueto, \& George, 2009). La televisión ha ocupado un importante lugar en sus vidas y han empezado a madurarla pues el verla como un simple divertimento les resta protagonismo a su faceta socializadora, a su capacidad de embaucar, a sus planteamientos manipulativos, a sus pretensiones consumistas... Ahora la analizan y reflexionan en voz alta.

El día noveno de clase empezamos como la vez anterior con nuestra propuesta de televisión. Igual que eligieron ellos, nosotros les traemos una propuesta. Por ello, nos valemos de autores para explicar y comprender una etapa de la historia de la televisión y de España en el contexto Europeo que va de los años 70 a la actualidad (según autores como: Manfredi (2004), Díaz (2006) y Moreno \& Jiménez (2007)). Y, de este modo, Chicho Ibáñez Serrador será uno de nuestro seleccionado con su programa concurso de éxito "Un, dos, tres, responda otra vez". Aquí hacemos un llamamiento al papel de las chicas/azafatas en la época del programa en blanco y negro y en la época del color; siempre por delante de las modas y mostrando una España que evolucionaba y se miraba en Europa. El siguiente autor es el vasco de prestigio internacional Antonio Mercero. Para ello, nos valemos de series como "Crónicas de un pueblo", aún en la España franquista, para pasar al cortometraje "La cabina", para seguir con la serie ambientada en Andalucía "Verano Azul" y, por último, "Farmacia de guardia" que muchos aún recuerdan por no haber pasado mucho tiempo de su emisión y haber cosechado varios premios y reconocimientos. Creemos que la clase se ha disfrutado y siempre hay un pretexto de la televisión más reciente que es motivo de debate y análisis. Sin ir más lejos en la primavera del año pasado (curso 20092010) se estrenó en Antena 3 una serie muy esperada sobre el Golpe de Estado de los años 80 en España donde el Rey, Juan Carlos I, tuvo un gran protagonismo. Un recurso para hablar de la televisión actual y cómo ésta puede adquirir la calificación de documento, aún siendo una ficción.

El último día de clase siempre concluimos con una salida para visitar las instalaciones de Canal Sur en Cádiz. Un edificio novísimo con tecnología de última generación que se nos explica con sumo agrado. Una persona nos atiende en el vestíbulo, nos da una pequeña charla sobre el ente andaluz de radiotelevisión pública, del desarrollo de la TDT, nos muestra ejemplos de lo que sería la televisión de alta definición, nos habla de cómo se genera una notica desde el momento que surge hasta que se emite, nos lleva por las diferentes dependencias: sea el plató, peluquería, sala de documentación, redacción y edición de la noticia. Todo un lujo que el alumnado en hora y media aprenden a descubrir la televisión por dentro.

Una experiencia que pasa por ver la televisión como un agente con intencionalidad, que hemos de tener y mantener una actitud crítica y responsable ante ella, que hemos de adquirir cierta cultura televisiva pero, también, alfabetizarnos en este discurso audiovisual. Lo importante no es ver la televisión sino aprender a mirarnos unos a los otros. La pantalla ha sido un pretexto para mantenernos 20 juntos y hablar sobre televisión del presente, del pasado y del futuro. Con una metodología de trabajo que fuera en todo momento motivadora, que de pie al quehacer individual como grupal, pero siempre con una consigna de activar al espectador/ alumnado para que adquiera una actitud participativa ante las pantallas, pues lo que se pretende es que siga investigando y descubriendo que la televisión posee una importante vertiente lúdica, que nos permite asomarnos a una ventana con muchísima información a la que hay que saber acceder y decodificar. Una forma de aprender y divertirse que tiene como pretexto a la televisión y al alumnado como protagonista, sin olvidar el contexto y los momentos históricos y televisivos que experimentaron.

\section{Referencias}

Amar, V. (2003). Comprender y disfrutar el cine: la gran pantalla como recurso educativo. Huelva: Comunicar.

Amar, V. (2009). El cine yotras miradas. Contribuciones a la educación y a la cultura audiovisual. Sevilla-Zamora: Comunicación Social.

Bourdieu, P. (1997). Sobre la televisión. Madrid: Anagrama.

Castillo, J. M. (2009). Televisión, realización y lenguaje audiovisual. Madrid: IORTV.

Chicharro, M., \& Rueda, J. (2005). Imágenes y palabras. Medios de comunicación y públicos contemporáneos. Madrid: CIS.

Díaz, L. (2006). 50 años de TVE. Madrid: Alianza.

Ferrés, J. (1994). Televisión y educación. Barcelona: Paidós.

García Matilla, A. (2003). Una televisión para la educación: la utopía posible. Barcelona: Gedisa.

Gimeno Sacristán, J. (2009). Pedagogía por objetivos: obsesión por la eficacia. Madrid: Morata. 
Hartley, J. (2000). Los usos de la televisión. Barcelona: Paidós.

Hernández, Fernando, \& Sancho, J. M. (2002). Para enseñarno basta con saber la asignatura. México: Editorial Paidós Mexicana.

López, F., Cueto, E., \& George D. R. (2009). Historias de la pequeña pantalla. Representaciones históricas en la televisión en la España democrática. Madrid: Vervuert Iberoamericana.

Manfredi, J. (2004). La televisión pública: transformación en el estado del bienestar. Sevilla: Instituto andaluz de administración publica.

Martín Barbero, J. (2000). Los ejercicios de ver. Hegemonía audiovisual y ficción televisiva. Barcelona: Gedisa.
Meirieu, P. (2009). ¡Otra televisión es posible! Madrid: Popular.

Moreno, E., \& Jiménez, E. (2007). Los desafíos de la televisión pública en Europa. Navarra: Eunsa.

Rodríguez Pastoriza, F. (2003). Cultura y televisión: una relación de conflicto. Barcelona: Gedisa.

Tubella, I., \& Dwyer, V. (2008). Internet y televisión: la guerra de las pantallas. Barcelona: Ariel. 